\title{
Using Online Visual Merchandising (OVM) to Enhance Web Usability (A study on E-government Websites in Egypt)
}

\author{
Alaa El-Gammal ${ }^{1 *} \quad$ Tamer Abdellatif $^{2}$ Dina Abboud ${ }^{3}$ \\ 1- MScStudent, Graphics and Media ArtsDep., Faculty of Arts andDesign, MSA University \\ 2- Professor, Faculty of Applied Arts,Helwan university ,Advertising Department \\ 3- Professor ,Graphics and Media ArtsDep., Faculty of Arts andDesign, MSA University
}

\begin{tabular}{l|l|l|l|} 
Submit Date: 2021-09-15 22:10:42 & Revise Date: 2021-12-10 11:43:22 & Accept Date: 2021-12-18 19:25:32
\end{tabular}

DOI: 10.21608/jdsaa.2021.96316.1129

\section{KEYWORDS:}

Online visual merchandising (OVM), E-government, Human-computer Interaction (HCI), Usability testing, Web Accessibility, Visual impairments.

\begin{abstract}
:
Every business website, blog, and online store aspires to enhance traffic, brand loyalty and customer engagement in order to boost sales. Changes that happen in online visual merchandising strategies can help to improve the virtual environment by responding to consumer needs for online sensory experiences and easy access to information.

Enhanced human-computer interaction (HCI) knowledge organization to support interface and web design activities, complementing recognized and effective usability methods (such as usability testing, etc.)

Affecting design elements are identified through web content analysis, the results of which are utilized to develop specific implications for improving web accessibility for people with physical or visual impairments.

Therefore, this paper aims to apply a mixed-methods approach to examine e-government websites in Egypt in order to reveal the usability strategies and accessibility used in developing its user interface.

This study focuses on if there is a hypothesized link between the visual merchandising techniques used on those sites and the efficiency of e-government and e-commerce/e-service sites (as measured by traffic data).

Developing new design models for differencing user groups and implementing web accessibility strategy are emphasized as vital steps towards effective information dissemination via e-government websites have been suggested as one of the finest steps towards making the web content accessible for users with differing needs.
\end{abstract}




\section{1- Introduction:}

The use of online visual merchandising reduces the consumer's perceived risk, allowing Internet-based shopping to compete with-or supplement-traditional sales channels.

As computer techniques and tools develop dynamically, and the number of web applications grows, the importance of the problem of accessibility grows as well. Considering the undeniable role of websites in the success of interactions between citizens and governments, evaluating e-government websites is a worthwhile topic Dahooie et al. (2020).

The growing of technology has a significant impact on the direction and pace of human life. This technology has created the internet of things also the growth of online markets. The number of e-commerce that grows and develops certainly makes the e-commerce compete with each other. So, with the growing competition in the online market, websites have gained vital importance for organizations S. Roy, P. K. Pattnaik and R. Mall (2014).

Through visual stimulation and other techniques of communication, visual merchandising is a significant marketing tool for retail companies (Lea-Greenwood, 1998; McGoldrick, 2002; Pegler, 2001; Grossbart, et al. 1990). The exact translation of visual merchandising is "display of goods," however this is rather narrow, given the wide range of actions it covers.

Pegler (2001) defines it as "the method of presentation of the product intended to communicate the concept of the same product to consumers in order to maximize sales and profits."

Bruun, A., Stage, J., (2015) Usability is quality attribute for software applications that indicates to what extent identified goals can be accomplished with effectiveness, efficiency and satisfaction by users.

Thus, Usability testing is important for user satisfaction by measuring how user-friendly the application is by examining whether the design makes it easy for users to perform tasks such as finding information, purchasing goods, or enjoying entertainment (depending on the purpose of the site), code compatibility and portability are also issues in usability testing of e-commerce applications, as they are accessed on a variety of platforms (mobile, computer, tablet, etc.) and operating systems (Windows, macOS, Android, IOS, etc.).

T. S. Tullis and J. N. Stetson (2004) Usability and Accessibility are the core concepts of human computer interaction (HCI).

Accessibility is a critical factor for e-commerce success. Good (2008, p. 16) defines accessibility in a more versatile manner which definition encompasses the contextual requirements of developing countries. The definition goes as, "A website is said to be accessible to anyone, regardless of economic, geographic or physical circumstances, is able to access it". However, physical and visual impairments of users have a considerable influence on the accessibility of web page user interface (UI) if it has been designed without full consideration of the needs of all users. Especially, visual and mobility impaired users experience poor accessibility. Poor readability and less navigable page designs are two observable issues, which pose threats to accessibility.

However, it is currently noted that there is not enough evidence that existing guidelines or design pattern organization systems have significant positive effect in practical interaction design as mentioned by $\mathrm{A}$. Dearden and J. Finlay. (2006).

Thus, this research aims to explore how to enhance website usability, demonstrate the importance of interaction design and identify the impact of online visual merchandising. And to reach a validated results mixed method will be used.

\section{2- Online Visual Merchandising:}

Online product and services sales, according to eMarketer, are driving the rise of online shopping. Visual appeal on the screen is one of the few ways to communicate information to consumers in online selling, as it becomes increasingly widespread in our daily lives. It's crucial to figure out which visual merchandising variables have a major impact on customers' behavior. However, many consumers continue to avoid making purchases through online.

Kumar V. (2014) in his research paper "A study on Needs of Visual Merchandising for Online \& Physical Stores", said that the field of both retail store and online sites there is rise in the visual merchandising.

Therefore, there is an acute need for advancement and enrichment of online visual merchandising factors in order to amuse the customers by providing sensory experience, physical inspection and visual information in the online experience Khakimdjanova \& Park, (2005).

Erogluet al. (2001) suggest that images of the merchandise, music, icons, color, background patterns, animation, and fonts might have such effects. To begin theory building in this important area, the researchers point out the "need to systematically develop a comprehensive taxonomy of online atmospheric cues and identify their major dimensions"

From all of these, online or digital merchandising is the act of integrating visual aspects to enhance the whole experience by guiding users through their journey towards purchase decisions as quickly as possible, which can be defined as "The selection and presentation of products and content to make optimal use of screen".

2.1 Online Visual Merchandising main variables: Nagadeepa C. (2019) six important variables are considered to examine the effectiveness of online visual merchandising (product image quality, product presentation, websites visual appeal, website layout, website advertisement and promotional offers)

Gilliam C. (2015) explained how can you improve your online visual merchandising by doing things like 
investing in high-resolution and capitalizing photos because clear and professional taken photos are an asset to the brand, giving your customers a realistic view of the product, shooting videos to promote your product (which is one of the more expensive visual content but worth it), and making your home page striking and beautiful.

Katrandjiev H. and Velinov I. (2014), applied content analysis on randomly selected websites and by the help of content analysis they reveal the following structure of OVM which have two broad group high task relevant environment (HTRE) and low task relevant environment (LTRE) further both in total have five categories, under LTRE there are two (atmospheric feature and registration) and HTRE includes three (web navigation, web graphics and product demonstration).

If we go further, we can see there are thirteen elements within category - background color, text color, atmospheric features, and registration requirement within LTRE; site map, search engine, website geometry, presentation format, product view dimensionality, apparel color, product display method, and mix/ match option within HTRE. After these 55 sub elements were identified 17 sub elements within LTRE group and 38 sub elements within HTRE group.

Kumar A. \& Yinliang T. (2012) explained the importance of Product videos in e-commerce. According to the paper, a product video is a virtual product experience that is more similar to physical shopping, allowing customers to make better informed decisions.

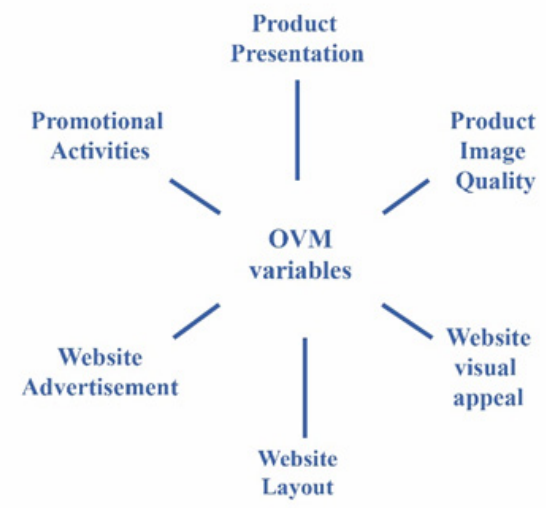

Figure 1: OVM variables

designed by the researcher (2021).

\section{3- Interaction Design:}

An important component of interaction design is the visual display of information, the origins of which are rooted in graphic design. The study of graphic design focuses on the organizational aspects of design and using the right visual cues to communicate with the user, whether it involves conveying the functionality of an object or evoking the right emotions.

According to Interaction \& Service Design Concepts (2016), Interaction design principles include the use of color, hierarchy, typography, grid layouts and com- position, all of which are used by interaction designers to facilitate user behavior and to create more usable interfaces. In fact, graphic designers have been working on computer interfaces since the emergence of the graphical user interface in the 1980s.

\subsection{Dimensions of Interaction Design:}

According to Usability Geek, Interaction design has five basic principles or what developers often call dimensions. These are:

- 1D: Words: on a website should be simple to understand while also conveying a lot of information - and they should speak to the proper demographic. The rule of thumb here is to utilize straightforward language with little, if any, fluff.

- 2D: Visual Representations: In the digital world, visuals refer to anything that isn't a word, such as typography, photographs, icons, infographics, and other graphical features. Images are the most effective technique to grab a user's attention. Users should be able to interact with them seamlessly using only their intuition.

- 3D: Physical Objects or Space: Cluttered web design has a negative impact on interaction since it makes it more difficult for visitors to interact with the many sections of websites. Keep in mind that the physical objects and spacing will differ by device.

- 4D: Time: Refers to how media can change over time, and how motion and sound can and do influence how a user navigates and interacts with a product. Also, how much time a user spends interacting with the product and how he/she might resume the interaction later.

- 5D: Behavior: Interaction design is concerned with how users interact with websites. To put it another way, how do the four elements above interact to influence a user's interaction with a product. The behavior dimension also considers users' emotional response and creates new recommendations based on that feedback in order to improve the user experience.

\subsection{Interaction design effect on user experience (UX)}

As Interactive design focuses on creating engaging interfaces with well thought out behaviors, online merchandising makes sure users see the most relevant services, in the best order, presented in the most compelling way.

According to Interaction Design Foundation, Interaction design, is "the practice of designing interactive digital products, environments, systems, and services." Beyond the digital aspect, interaction design is also useful when creating physical (non-digital) products, exploring how a user might interact with it is the design of the interaction between users and products. Most often when people talk about interaction design, the products tend to be software products 
like apps or websites.

There's a huge overlap between interaction design and UX design. After all, UX design is about shaping the experience of using a product or promoting service, and most part of that experience involves some interaction between the user and the product.

UX design is more than interaction design: it also involves user research (finding out who the users are in the first place), creating user personas (why, and under what conditions, would they use the product), performing user testing and usability testing.

\section{4- Usability:}

J. Díaz, C. Rusu, and C. A. Collazos. (2017) Usability of a website defines how easy a website is for users who interact with it. D. O. Olawole (2018) showed that better usability on an e-commerce website can increase the customer base, which can help grow the business.

If customers are satisfied with their experience and enjoy their visit, that may help rising the company's popularity.

A website must be built to be simple to use and accessible to all users, including those with disabilities. Websites with complex user interfaces are abandon by the customers. Hence, the usability and accessibility are an essential part of designing an e-commerce website.

As computer techniques and tools develop dynamically, and the number of web applications grows, the importance of the problem of accessibility grows as well. Considering the undeniable role of websites in the success of interactions between citizens and governments, evaluating e-government web sites is a worthwhile topic Dahooie et al. (2020).

\subsection{Usability testing:}

According to Samkit J. and Pradnya P. (2021) the Main four significant factors of usability testing of e-commerce applications are Connectivity, Readability, Accessibility, and Functional Performance.

- Connectivity: Connectivity of application means how fast the application loads. It depends on various elements like loading speed, page size, page speed, etc.

- Readability: Readability of application measures of how easily users can understand the pages and context.

- Accessibility: Accessibility of application points to well-structured coding, appropriate headers, images, and text. It defines the reach of the user group.

- Functional Performance: Functional Performance will include overall experience with different factors like how satisfying the website are likely to be for users, popularity, technology, headings, amount of content, server behavior, etc.

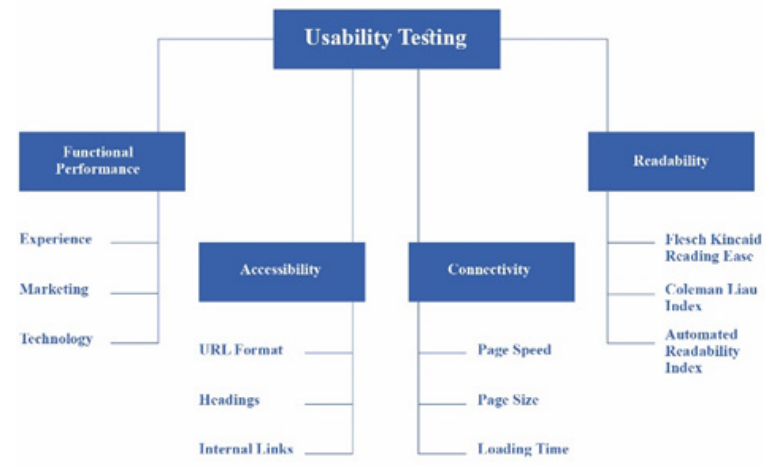

Figure 2: Model for Usability Testing of E-commerce Applications. Source: Samkit Jain and Pradnya Purandare (2021) diagram re-designed by the researcher (2021).

Website accessibility is particularly important for the elderly and people with disabilities such as the blind, visually impaired, motorically challenged, hard of hearing, deaf, dyslexic, or dysfunctional in any way Ismailova (2017).

An accessible website allows disabled individuals to access material and features independently, fully or restricted, safe and secure, taking into consideration the nature of activities of different user groups.

More broadly, website accessibility can mean the possibility to browse content comfortably, regardless of physical limitations Vollenwyder et al. (2019), search engine visibility (SEO visibility, also known as search visibility) Härting et al. (2016), social media visibility Bronner and de Hoog (2019), and web availability Rogers et al. (2017). These attributes make up website usability.

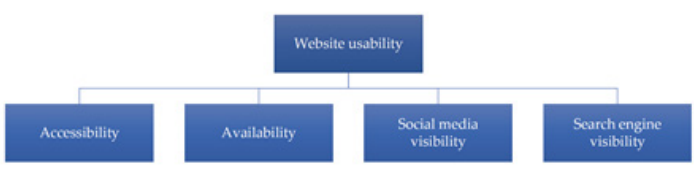

Figure 3: Ways website accessibility can be perceived.

Source: Król, Karol, and Dariusz Zdonek. (2020)

J. Nielsen, (2015) explain usability as being made up of five principles:

- Learnability: how easily can a new user learn to navigate the interface?

- Efficiency: how quickly can users perform tasks?

- Memorability: if a user hasn't visited the system in a while, how well will they remember the interface?

- Errors: how many errors do users make, and how quickly can they recover from errors?

- Satisfaction: do users enjoy using the interface, and are they pleased with the results? 


\section{5- Methodology:}

This research has been conducted to find out the perception, views and attitude of consumers towards online visual merchandising elements especially through consumers with visual impairments.

Thus, that has been done through two stages:

First stage: primary quantitative data have been collected through survey from consumers who use governmental services. The survey consists of two parts. The first part consists of demographic data age, educational level and city of residence of respondents. The second part consists of questions related to the attitude towards interacting with online services and if there is a link between web usability and visual merchandising elements.

Second stage: number of different governmental websites was examined by a focus group of 7 specialist in web design to discus which website is more appropriate for the analytical study.

An analytical study was done and conducted by the researcher on Egyptian National Railways website to find out how to reveal usability strategies and accessibility to develop its user interface taking in consideration the variables of online visual merchandising.

\section{6- Hypotheses}

H1: Website's Visual appeal and appropriate usage of OVM variables have a significant impact on consumers' behavior in trusting the website.

H2: Website Layout and applying dimensions of Interaction design have a significant impact on consumers' behavior.

H3: Implementing the factors of usability testing and web accessibility have a significant impact on consumers' behavior.

\section{7- Analytical Study:}

The Egyptian National Railways website was chosen to be analyzed by a focus group of 7 experts in web design.

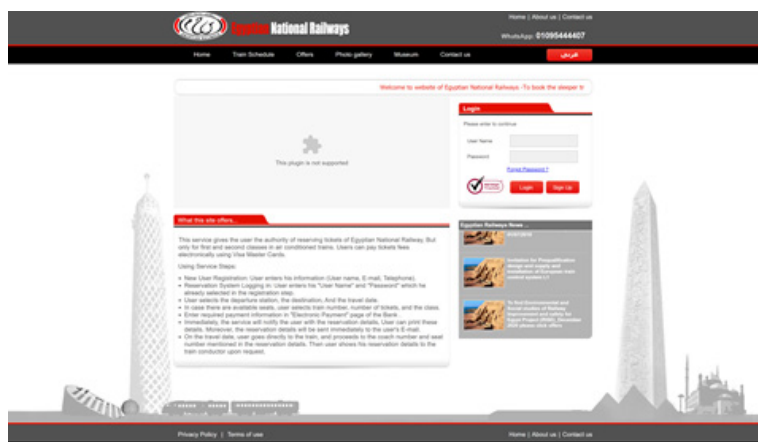

Home page contains pale colors and different sections but there is a lack of important data, poor layout structure.

It takes a time to reload the plugged image which can lead to a bad influence of how a user navigates and interacts the website.

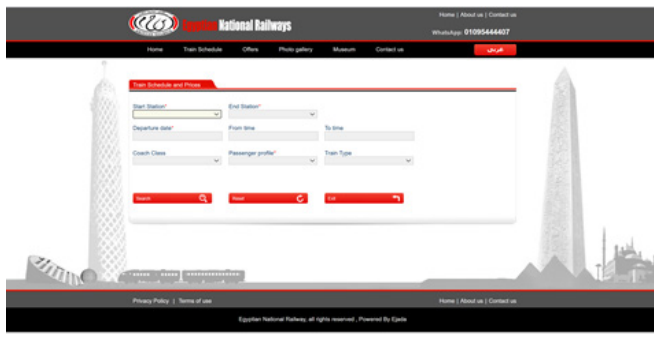

Train schedule page font style and text can be more readable than this especially on the red buttons with white text.

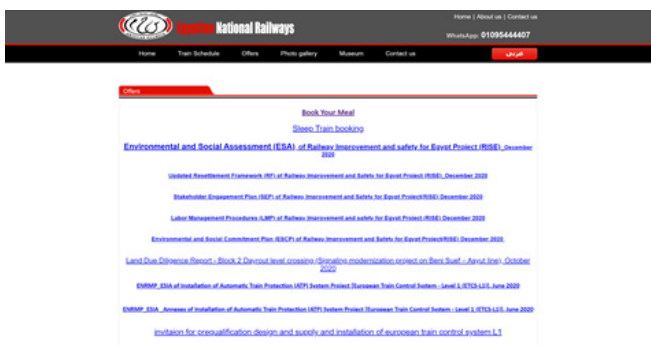

Offers page is in a lack of graphic design elements (images, videos, etc..) and accessibility features (well-structured coding, appropriate headers, images, and text).

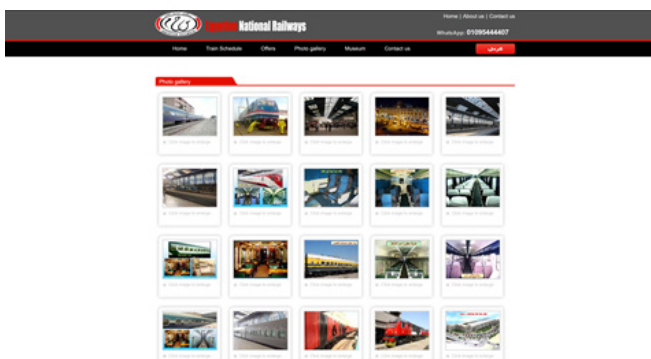

Photo gallery/ Museum page both pages have the same layout yet the images resolution is very low and there is no description added to explain more about the image.

\section{8- Findings and Discussion:}

The total number of participants in the survey was 120 , with the majority of $(55 \%)$ were dominated by the age group of $35-45$ Years and (30\%) by the age group of 25-35.

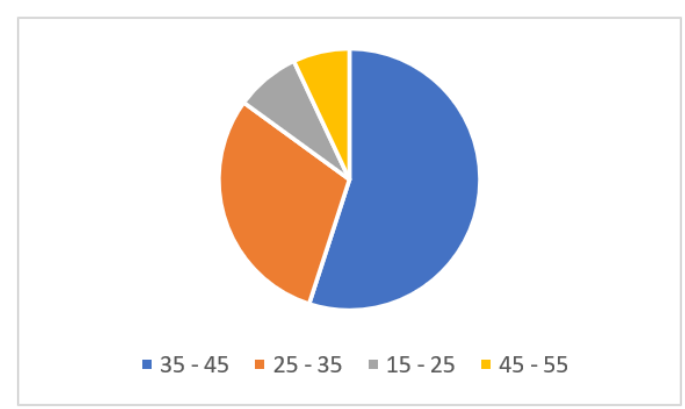


Approximately (75\%) of the audience once per month use the governmental services. And almost all the participants were comfortable with mobile and web applications. As per the survey, Egyptian National Railways and Health Insurance were the most used governmental services and application by the users followed by Gas, Electricity bills online paying and Traffic services.

As per as the survey (46\%) of consumers' experience while navigating the website is affected with their visual impairment specially when it comes to graphic design elements such as font style - text readability followed by colors and images quality and when it comes to layout and interface sizes and data organization were the most factors that affected their experience.

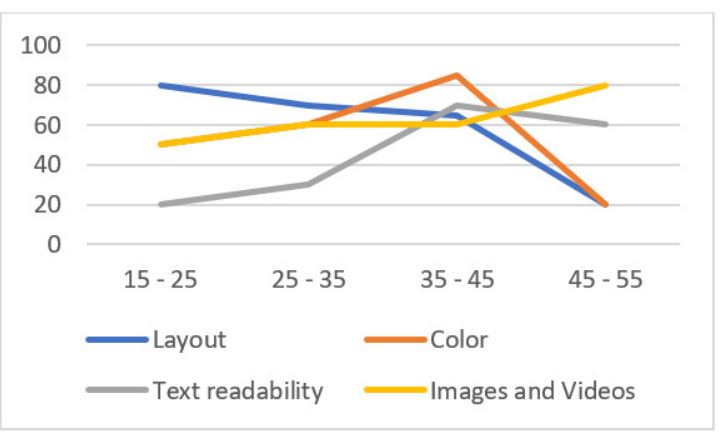

After examining the Egyptian railways website. According to the results, a good visual appeal might be the main reason in trusting a website, and image quality has its effect on memorability, in addition to the font style and text size and how could it affect the target group regarding their characteristics.

The website should present efficient and suitable information and data to cover the users' needs to increase website credibility.

Accordingly, we can confirm that developing new design models for differencing user groups and implementing OVM variables, dimensions of Interaction design and web accessibility strategies are recommended to fill this gap, because this issue arises the lack of trust towards the website.

\section{9- Conclusions:}

This research reveals that online Visual merchandising plays an important role in the process of framing the design strategies to enhance a good users experience among consumers with visual impairments. Online Visual merchandising techniques are used to attract the consumers by displaying their service/ product in innovative way to build a trusted relation between the consumers and website.

On the basis of the above findings, the research work concludes that online visual merchandising has a major effect on web usability and accessibility plays a significant role in consumers' decision.

This study confirmed that consumers' behavior towards a service is highly motivated by the website vi- sual appeal and secondly by website layout and finally service/product display image quality. Hence the service provider should focus on the remaining variables to make them a perfect promoting strategy to promote their service.

The government should take action to improve websites and their image towards consumers by apply principles of online visual merchandising and human-computer interaction design which improve e-government websites experience and achieve higher levels of user's satisfaction through a deep understanding of consumers' needs and find a link between this understanding and the efficiency of e-government and e-commerce/e-service sites.

\section{0- References}

A. Dearden and J. Finlay. 2006, Pattern languages in HCI: A critical review, Human-Computer Interaction, vol. 21, no. 1, pp. 49-102.

Bronner, Fred, and Robert de Hoog. 2019, Conspicuous leisure: The social visibility of cultural experiences, International Journal of Market Research 61: $430-46$.

Bruun, A., Stage, J., 2015, New approaches to usability evaluation in software development: Barefoot and crowdsourcing, J. Syst. Softw. 105, 40-53.

Card, S., Moran, T., \& Newell, A. 1983, The psychology of human-computer interaction. Hillsdale, NJ: Lawrence Erlbaum Associates.

Dahooie, Jalil Heidary, Amir Salar Vanaki, Sajedeh Daneshmoghadam, and Edmundas Kazimieras Zavadskas. 2020, A Framework to Overcome Hesitancy of Decision-Makers in E-Government Web Site Evaluation, International Journal of Fuzzy Systems 22: 583-603.

Eberts, R. E. 1994, User interface design. Englewood Cliffs, NJ: Prentice Hall.

Eroglu, S.A., Machleit, K. and Davis, L. 2001, Atmospheric qualities of online retailing: a conceptual model and implications, Journal of Business Research, Vol. 54, pp. 177-84.

Gilliam C. 2015, Visual Merchandising your online store: what you need to know, retrieved January 11, 2018.

Good, A., 2008, An Investigation of a Method for Improving Accessibility to Web-Based information for Users with Impairments. Doctoral Thesis, University of Portsmouth, Portsmouth.

Grossbart, S., Hampton, R., Rammohan, B., \& Lapi $\neg-$ dus, R. S. 1990, Environmental dispositions and 
customer response to store atmospherics, Journal of Business Research, 224-225

Härting, Ralf-Christian, Maik Mohl, Philipp Steinhauser, and Steinhauser Michael Möhring. 2016, Search engine visibility indices versus visitor traffic on websites. In International Conference on Business Information Systems, Cham: Springer, pp. 91-101.

Hussain, A., Mkpojiogu, E. O., Abubakar, H., \& Hassan, H. M. Oct. 2017, The usability evaluation of mudar my on mobile device, In AIP Conference Proceedings (Vol. 1891, No. 1, p. 020058), AIP Publishing LLC.

Interaction \& Service Design Concepts: Principles, Perspectives \& Practices 2016, Writings at Carnegie Mellon School of Design by the Master of Design \& Master of Professional Studies Students.

Ismailova, Rita. 2017, Web site accessibility, usability and security: A survey of government web sites in Kyrgyz Republic, Universal Access in the Information Society 16: 257-64.

J. Díaz, C. Rusu, and C. A. Collazos, Feb. 2017, Experimental validation of a set of cultural-oriented usability heuristics: e-Commerce websites evaluation, Compute. Stand, Interfaces, vol. 50, pp. 160-178.

J. Nielsen, 2015, Preventing User Errors: Avoiding Unconscious Slips, NN/g Nielsen Norman Group World Leaders in Research-Based User Experience.

Khakimdjanova, L., \& Park, J.H. 2005, Online visual Merchandising practice of apparel e-merchants, Journal of Retailing and Consumer Services, 12(5), 307318.

Król, Karol, and Dariusz Zdonek. 2020, Local Government Website Accessibility-Evidence from Poland, Administrative Sciences 10, no. 2: 22. https:// doi.org/10.3390/admsci10020022

Kumar A. \& Yinliang T. 2012, Value of IT in online visual merchandising: A randomized experiment to estimate the value of online product video, retrieved on January 12, 2018 from http://www.krannert.pu rdue.edu/faculty/kkarthik/wise12/papers/wise12 submission_63.pdf

Lea-Greenwood, G. L. 1998, Visual merchandising: A neglected area in UK fashion marketing, International Journal of Retail \& Distribution Management, 26(8), 324329. doi:10.1108/09590559810231797

McGoldrick, P. J. 2002, Retail Marketing (2nd Edition), McGraw-Hill/China Machine Press, Hong Kong

Nagadeepa C. May,2019, Online Visual Merchandising:
Impact On Consumers' Impulse Buying Behaviour Among College Students, Kristu Jayanti College/Bengaluru, Karnataka, India.

O. Olawole, Nov.2018, User experience: tool for Human-Computer Interaction (HCI) design, AFRREV STECH An Int. J. Sci. Technol., vol. 7, no. 2, p. 61.

Pegler, M. 2001, Visual Merchandising and Display. New York: Fairchild Publications.

Rogers, Mary, Kelsey Lemmen, Rachel Kramer, Jason Mann, and Vineet Chopra. 2017, Internet-delivered health interventions that work: Systematic review of meta-analyses and evaluation of website availability, Journal of Medical Internet Research 19: e90.

S. Roy, P. K. Pattnaik and R. Mall, 2014, A quantitative approach to evaluate usability of academic websites based on human perception, Egypt. Inf. J. 15 (3), p. 159-167.

Samkit Jain and Pradnya Purandare 2021, J. Phys.: Conf. Ser. 1964042059

T. S. Tullis and J. N. Stetson, 2004, A Comparison of Questionnaires for Assessing Website Usability, Usability professional association conference.

Vollenwyder, Beat, Glena H. Iten, Florian Brühlmann, Klaus Opwis, and Elisa D. Mekler. 2019, Salient beliefs influencing the intention to consider Web Accessibility, Computers in Human Behavior 92: 352-60

\section{Websites:}

Interaction Design Organization (Accessed: 9 December 2021), URL:https://www.interaction-design.org/literature/ article/what-is-interaction-design

Usability Geek (Accessed: 9 December 2021), URL: https://usabilitygeek.com/introduction-interaction-design 